\title{
Impacts of beel nursery management on the variation of indigenous fish species and its socio-economic profitability: a study in the Dhaka beel, Bangladesh
}

\author{
Islam $\mathrm{KR}^{1}$, Sarker $\mathrm{BS}^{2}$, Nazrul $\mathrm{KMS}^{3 *}$, Tonny $\mathrm{US}^{3}$ and Faruque $\mathrm{MO}^{1}$ \\ ${ }^{I}$ Department of Aquaculture, ${ }^{3}$ Department of Fisheries Biology and Genetics, Bangladesh Agricultural \\ University, Mymensingh-2202, Bangladesh; ${ }^{2}$ Department of Fisheries and Marine Science, Noakhali Science \\ and Technology University, Noakhali-3202, Bangladesh.
}

[Received: July 25, Accepted: September 11, 2012]

\begin{abstract}
A research work was conducted to observe the beel management of the Dhaka beel situated in Tangail district, Bangladesh. Data were collected through questionnaire survey, discussion and interviewing. Dhaka beel is a 13 ha semi-enclosed beel brought under the nursery management project in 2010. The beel was stocked with approximately 100000 fish larvae of 4 days old during May to June. After 60 days of proper management the stocked larvae were sampled and 70,000 of fry were obtained. In the studied beel the annual production was 2.4 $\mathrm{mt}$ in 2009 where beel nursery management has increased the production to $7.10 \mathrm{mt}$ in 2010 which also included several non-stocked indigenous fish species. Socio-economic conditions of people were also improved where $80 \%$ of the people believed that it was true. Beel management has played an important role to minimize the rapid reduction of many important indigenous species through four to five months of management where fishes got the chance of recruitment. Management, guarding, harvesting, and income were equally shared among the group members. Findings of the present study suggest that beel nursery management can be an excellent scope for improvement of fish production and socio-economic status of the adjacent people.
\end{abstract}

Keywords: Beel, nursery management, recruitment, socio-economic

\section{INTRODUCTION}

Bangladesh possesses enormous area of wetlands including rivers and streams, freshwater lakes and marshes, haors, baors, beels, water storage reservoirs, fish ponds, flooded cultivated fields and estuarine systems with extensive mangrove swamps. The haors, baors, beels and jheels are of fluvial origin and are commonly identified as freshwater wetlands. These freshwater wetlands occupy four landscape units - floodplains, freshwater marshes, lakes and swamp forests. The fisheries sector includes open water bodies such as rivers, canals, lakes, etc. and closed water bodies such as ponds and flood-control polders totaling 4 million hectares. The rivers, beels (permanent and seasonal lakes and wetlands), baors (oxbow lakes), haors (large deeply flooded depressions), and floodplains support some 265 fish species ${ }^{[1]}$.

Fish and Fisheries sector play an important role on the socio-economic development of Bangladesh from the time immemorial and it is the part of our cultural heritage. There is growing acceptance in government policy in Bangladesh that the rural poor should be active participants in planning of development and in management of the resources they depend on. Now fish resources, particularly inland capture fisheries, appear to be in decline and some 10 million traditional fishers face poverty and loss of fishing rights ${ }^{[2]}$. The Jatio Matshayajibi Samity (JMS) or National Fishermen Association believes that this failure to achieve Bangladesh's fisheries potential is due mainly to lack of an appropriate fisheries management policy ${ }^{[2]}$. The government has always been interested in earning revenue from fisheries rather than biologically sound management.

Inland fisheries alone cover an area of 4.3 million hectares of which $94 \%$ comprise open water capture fisheries, and only $6 \%$ close water system. The haors, beels and baors offer tremendous scope and potential to augment fish production by adoption of culture-based fishery enhancement technique. The haors, beels and baors are the main source and reserves of the brood stock of fish. Tangua is one of the famous breeding ground for native crabs and flat fishes ( $N$. chitala) of the country. Among the available fisheries resources beel is the one but its contribution is not increasing at the same rate. As there are vast areas of beel $(1,14,161 \mathrm{ha})$ an estimate of 1.02 lakh $\mathrm{mt}$ production is possible from proper management ${ }^{[1]}$.

Among 260 freshwater fishes 143 species are considered small indigenous species (SIS) in our country. All of these species were found availably in beel water bodies a few years back, whereas, 57 of them are now threatened ${ }^{[3]}$. As a consequence the total composition of the fish species have been changed in the beel fisheries. In the studied Dhaka beel no management technique was operated in past. However, establishment of an appropriate nursery ground contributed to increase the fisheries production in a significant scale. This research work is therefore conducted to focus on the importance of beel nursery management. The specific objectives were: 1) to evaluate the potential importance of the beel management; 2) to determine fish species 
composition and their yield; 3) to compile the information about the household communities around the beel areas and 4) to evaluate farmer's dependency level on the beel fisheries.

Table 1: Status of indigenous fish species in the Dhaka beel.
Secondary data was collected through literature and publications available from Upazila Fisheries Office, quarterly and annual reports. Books of Bangladesh Bureau of Statistics were used to cross- check, complement or illustrate the primary data obtained through the survey and group discussion.

\begin{tabular}{|c|c|c|c|}
\hline Critically endangered & Endangered & Vulnerable & Not threatened \\
\hline Nonta & Kalibaus & Tangra & Punti \\
\hline Catal & Silvercarp & Baim & Taki \\
\hline Boal & - & - & Shol \\
\hline
\end{tabular}

\section{MATERIALS AND METHODS}

Study area:

The survey was undertaken in the Dhaka beel (13ha) which is one of the most important beels in Madhupur upazila located in the Tangail district Bangladesh. The survey was conducted from February to September, 2011.

Table 2: Sampled fish species variation.

\section{Editing and tabulation of the data:}

After collection, the data were edited for analysis. In order to minimize error, data were collected in local units and later, local units were converted into standard units. After completing the data collection, processed data were transferred to a master sheet and completed with a view to facilitate tabulation. Considering the objectives a list of tables were prepared. For completing the study a distinct list of steps was followed (Figure 1).

\begin{tabular}{|l|c|c|c|c|}
\hline \multicolumn{1}{|c|}{ Species } & \multirow{2}{*}{$\begin{array}{c}\text { Stocking Size } \\
(\mathrm{cm})\end{array}$} & \multirow{2}{*}{$\begin{array}{c}\text { Stocking } \\
\text { number } \\
\end{array}$} & & \multicolumn{2}{c|}{ After 60 days } \\
\cline { 4 - 5 } & & 45 aproximate $)$ & Size(cm) & Number (approximate) \\
\hline Rui & $0.5-1$ & 45000 & $5-6$ & 35000 \\
\hline Catla & $0.5-1$ & 20000 & $5-6$ & 14000 \\
\hline Mrigal & $1.5-2$ & 33500 & $6-7$ & 20000 \\
\hline Common carp & $1.5-2.5$ & 1500 & $7-8$ & 1000 \\
\hline & & 100000 & & 70000 \\
\hline
\end{tabular}

\section{Research approach and technique:}

The quantitative data were collected by reconnaissance survey while qualitative information was explored by case studies as the primary tools of data collection ${ }^{[4]}$.

Table 3: Seasonal yield of fishes in the studied beel.

\begin{tabular}{|l|c|c|c|c|}
\hline \multirow{1}{*}{ Yield } & $\begin{array}{c}\text { Apr - } \\
\text { early } \\
\text { Jun }\end{array}$ & Jun - Sep & \multicolumn{1}{c|}{$\begin{array}{c}\text { Oct - } \\
\text { Dec }\end{array}$} & $\begin{array}{c}\text { Dec - } \\
\text { Mar }\end{array}$ \\
\cline { 2 - 5 } & \multicolumn{4}{|c|}{ Seasons } \\
\cline { 2 - 5 } & $\begin{array}{c}\text { Pre } \\
\text { monsoon }\end{array}$ & Monsoon & $\begin{array}{c}\text { Post } \\
\text { monsoon }\end{array}$ & $\begin{array}{c}\text { Dry } \\
\text { season }\end{array}$ \\
\hline Peak & $\longrightarrow$ & $\longrightarrow$ \\
\hline Medium & \multicolumn{3}{|}{$\longrightarrow$} \\
\hline Low & \multicolumn{3}{|c}{} \\
\hline
\end{tabular}

Method of data collection:

Primary source:

Primary information was provided directly by the fishermen through direct observation, interviews and discussions. To obtain primary data, the study employed some techniques such as key informant's interview, participatory rural appraisal (PRA) with focus group discussions (FGD), observations, and documents screening time to time.

Secondary sources:
Processing and analysis of data:

All the collected data were processed and analyzed by statistical analyzing software Microsoft-excel and SPSS version 15.0.

\section{RESULTS AND DISCUSSION}

Overview of the beel resources:

Fish biodiversity has been degraded due to many reasons such as lack of proper management, overfishing, aquaculture practice, exotic species, habitat loss and degradation, sedimentation, pollution, alterations to hydrology, dredging etc. thus the availability of indigenous freshwater fish species of Bangladesh have declined to a great extent over the years and many of them are either rare or at the verge of extinction.

Preparation of nursery pond is essential for getting good production from the beel. In the study area, dike repairing was the main activity as pre stocking management because dike is important for holding water in the pond, fish cannot escape from the pond, the observation and management of the pond is easy, the polluted water cannot enter into the pond, mouse or crab cannot create hole, and harmful animals like snake, mongoose etc. cannot enter into the pond. Other works such as removing unwanted species, aquatic weeds, and excessive mud from the bottom, drying and applying lime 
and fertilizers were also done as pre-stocking management.

Table 4: Species variation in the Dhaka beel. are vulnerable. From the study it was found that nonta, boal, kalibaus etc. are not found today from the Dhaka beel (Table 1).

\begin{tabular}{|c|c|c|c|}
\hline \multicolumn{1}{|c|}{ Stocked species } & $\begin{array}{c}\text { Average weight of fish } \\
\text { species }\end{array}$ & $\begin{array}{c}\text { Non stocked species } \\
\text { (Before) }\end{array}$ & $\begin{array}{c}\text { Non stocked species } \\
\text { (After) }\end{array}$ \\
\hline Rui & $0.50 \mathrm{~kg}$ & Boal & Boal \\
\hline Catal & $0.58 \mathrm{~kg}$ & Guji & Tangra \\
\hline Mrigal & $0.65 \mathrm{~kg}$ & Tangra & Taki \\
\hline Common carp & $0.75 \mathrm{~kg}$ & Mola & Mola \\
\hline- & - & Veda & Baim \\
\hline- & - & Baim & Nonta \\
\hline- & - & - & Kalibaus \\
\hline- & - & - & Rajpunti \\
\hline- & - & - & Silver carp \\
\hline- & - & - & \\
\hline
\end{tabular}

Most of the farmers (90\%) controlled or removed unwanted species manually, $85 \%$ farmers used netting method and $10-15 \%$ farmers did not use any chemicals or other methods ${ }^{[5]}$. The chemicals and other toxic substances used for controlling aquatic weeds, pests, predators and undesirable species were rotenone, phostoxin, dipterex, bleaching powder, diesel, sumithion endrin, copper sulphate, aldrin and DDT ${ }^{[6]}$. In the present study, it was found that farmers removed predatory fish by drying the nursery pond. Aquatic insects such as hash poka usually destroy the small PL, for this reason diesel or kerosene were spread over water in each decimal at the rate of $125 \mathrm{ml}$ before one day of releasing PL in nursery pond.

Table 5: Production in Dhaka beel before (2009) and after (2010) management.

\begin{tabular}{|c|c|c|c|}
\hline Year & $\begin{array}{c}\text { Target of } \\
\text { production } \\
(\mathrm{mt})\end{array}$ & $\begin{array}{c}\text { Annual } \\
\text { production } \\
(\mathrm{mt})\end{array}$ & $\begin{array}{c}\text { Market } \\
\text { value of } \\
\text { fishes } \\
\text { (lakh) }\end{array}$ \\
\hline 2009 & 6.5 & 2.4 & $1.31 \mathrm{tk}$ \\
\hline 2010 & 9.7 & 7.10 & $3.9 \mathrm{tk}$ \\
\hline
\end{tabular}

In the present study, it was found that the PL and carp fries were mainly dependent on natural feed. For this, weeds were removed and accumulated near the nursery pond which was decomposed and produced good quality natural feed. However, small amount of supplementary feeds produced from local ingredients like oil cake, flour, salt etc were also given after the stocking.

Water depth variation in Dhaka beel:

The average water depth in Dhaka beel was found the highest of $6 \mathrm{ft}$ from July-September and the lowest depth of water was observed in JanuaryMarch (Figure 2). The average depth of ponds in Bangladesh is $2-5$ meter ${ }^{[7]}$. In the present study, it was found that 3-4 feet is the suitable depth for nursery water body.

Biodiversity status of indigenous fish species in the Dhaka beel:

Different species of fish which were abundant in Dhaka beel are now in great threat. Some of them are already been extinct, some are threatened, and some
Stocking and monitoring:

Before stocking the beel, a suitable nursery pond was selected in the beel area. After preparation the beel was stocked with the larvae of 4 days old during May to June. Approximately 100000 larvae were stocked where rui, catla, mrigal and common carp were dominant. The aim was to give minimum input and to get maximum output. A committee was build up to monitor the nursery pond. Feeding of the larvae was done by the beneficiary group.

Management regime:

For managing the beel nursery project a management committee was established. The beel nursery management committee included the upazila nirbahi officer (UNO), local chairman, upazila fisheries officer (UFO) and the fisheries community around the beel. There, the beneficiary group performed all kind of rearing and monitoring activities.

Variation of larval performance:

The stocked larvae were sampled after 60 days. The average size range of the sampled fishes was 5-6 cm. From the stocked larvae 70000 of fry were obtained (Table 2) ${ }^{[8]}$. A highly significant variation was found for the stocked and harvesting fry size $(P \leq 0.0001)$ whereas a non-significant variation was found for stocking and harvesting number of fry $(P \leq 0.55)$. From the sampling of the stocked fishes it was observed that rui was higher in number than others species. As the beel has connection with the perennial khal many non-stocked species was encountered in the final harvest although many of them were not found before management.

Seasonal yield of fishes:

Fishes were found in moderate amount during rainy season. However, the captures were high in the pre and post-monsoon. In dry season production was severely reduced (Table 3 ).

Fish species harvested from the Dhaka beel by fishers groups in 2009-2010:

Harvesting of the fishes gave the result of a large number of non stocked fishes like guji, raj punti, boal etc. The average growth rate of the stocked and non stocked fishes was satisfactory. However, the number of the non stocked species of fishes was 
higher than the stocked species in the final harvest (Table 4).

Table 6: Overview of fisheries comparison in Dhaka beel before (2009) and after (2010) management.
Educational status:

Most of the fishermen were illiterate (80\%). Only small portion of them could sign only $(5 \%)$. Some were primary level of educated $(15 \%)$. None of the fishermen were from secondary level. Most of the

\begin{tabular}{|c|c|c|}
\hline Issue & $\begin{array}{c}\text { Position before beel nursery } \\
\text { management }\end{array}$ & $\begin{array}{l}\text { Position after beel nursery } \\
\text { management }\end{array}$ \\
\hline Fishers engaged in fishery & $70-80$ & $120-130$ \\
\hline Annual government revenue & 1.31 lakh tk & 3.9 lakh tk \\
\hline Fish production & Nature dependent & $\begin{array}{l}\text { From nature and stocking (culture } \\
\text { based) }\end{array}$ \\
\hline Fish species & $\begin{array}{l}\text { Koi,sing,lati,punti,etc.(mainly } \\
\text { native catfish and small fish) }\end{array}$ & $\begin{array}{l}\text { Native catfish plus stocked carp (rui, } \\
\text { catla, mrigal etc) }\end{array}$ \\
\hline $\begin{array}{l}\text { Quantity of fish produced } \\
\text { annually }\end{array}$ & $2.4 \mathrm{mt}$ & $7.10 \mathrm{mt}$ \\
\hline $\begin{array}{l}\text { Average annual per capita fisher } \\
\text { income }\end{array}$ & 25000 tk & $45000 \mathrm{tk}$ \\
\hline Socioeconomic condition of fisher & $\begin{array}{l}\text { Subsistence survival under the } \\
\text { exploitation of debt to izaradar }\end{array}$ & $\begin{array}{l}\text { After maintaining minimum standard } \\
\text { of living fishers able to save }\end{array}$ \\
\hline Fishing right & $\begin{array}{c}\text { Fishers caught fish on payment of } \\
\text { toll to izaradar }\end{array}$ & $\begin{array}{c}\text { Fishers have the right to their own } \\
\text { fish }\end{array}$ \\
\hline
\end{tabular}

Comparative production in the stocked Dhaka beel and the non stocked Adaburi beel:

From the present study it was found that the annual fisheries production in the Dhaka beel was higher than the Adaburi beel in the Alokdia union. It was a 30 hec semi-enclosed beel. It was outside of the nursery management. The annual fisheries production from this beel was about $0.75 \mathrm{~kg} / \mathrm{dec}$. This production is severely lower than the managed Dhaka beel where the production was $2.75 \mathrm{~kg} / \mathrm{dec}^{[8]}$.

\section{Socio economic status of the people:}

The overall impact on the variation of indigenous fish species of beel nursery management and its social and economic profitability were described by giving emphases on age structure, religion, educational status, family size, housing condition, health facilities, sanitary facilities, sources of drinking water, income level, gears used and government assistance. A total of 40 fishermen were interviewed for data collection.

Age structure:

Different categories of age groups like young (20-30 years), middle aged (31-50 years) and old (51-60 years) were considered to examine the age structure. It appeared that age group of 31-50 years was the highest (50\%) and 51-60 years was the lowest (10\%) and 20-30 years was $40 \%$ when considering all fishermen. It was found that most of the fish farmers (50\%) belonged to age group of 31 to 40 years in Mymensingh district ${ }^{[9]}$. Age structure of fishermen at Sundarbans ranged from 20 to 70 years ${ }^{[10]}$. Both of these studies are more or less similar to the present findings. fishermen were compelled to enter into the fishing profession in their early age due to poor economic status of their parents and lack of awareness about education. Another important factor was that, there was hardly any educational institution in the areas of fishing villages. For above reasons, most of the riverine fishermen were illiterate.

Religious view:

The fishing communities of Bangladesh include people of various castes, creed and status. Though conceived anthropologically that the low caste Hindus constitute the fishing communities in Bangladesh, by the process of social and economic mobility people from other religions have already been dominating over fishery sector especially inland capture fishery. Representation of Hindus was very much negligible. About $85 \%$ and $15 \%$ fishermen were found to be Muslims and Hindus respectively. The dominance of Muslims may be understood on the ground of changing socio-economic structures, lack of employment opportunity and realization of the riverine fishing potential as a source of income. It was found that $77.78 \%$ fishermen were Muslim and $22.22 \%$ fishermen were Hindus in the Mymensingh region ${ }^{[9]}$.

Family types:

From the study it was found that, $60 \%$ fishermen families were jointed and rest were nuclear. About $42.5 \%$ of the fishermen lived in nuclear family and the rest $(57.5 \%)$ in joint family in Mymensingh district ${ }^{[9]}$.

Occupational status:

Most of the fishermen around the Dhaka beel were involved in fishing as their main occupation. However, some were also engaged in agriculture and day labor as their main occupation. The present study 
has revealed that $89 \%$ of fishermen were engaged in fishing as their main occupation, $11 \%$ was in agriculture and other different business which is more or less similar to findings of other researchers [11].

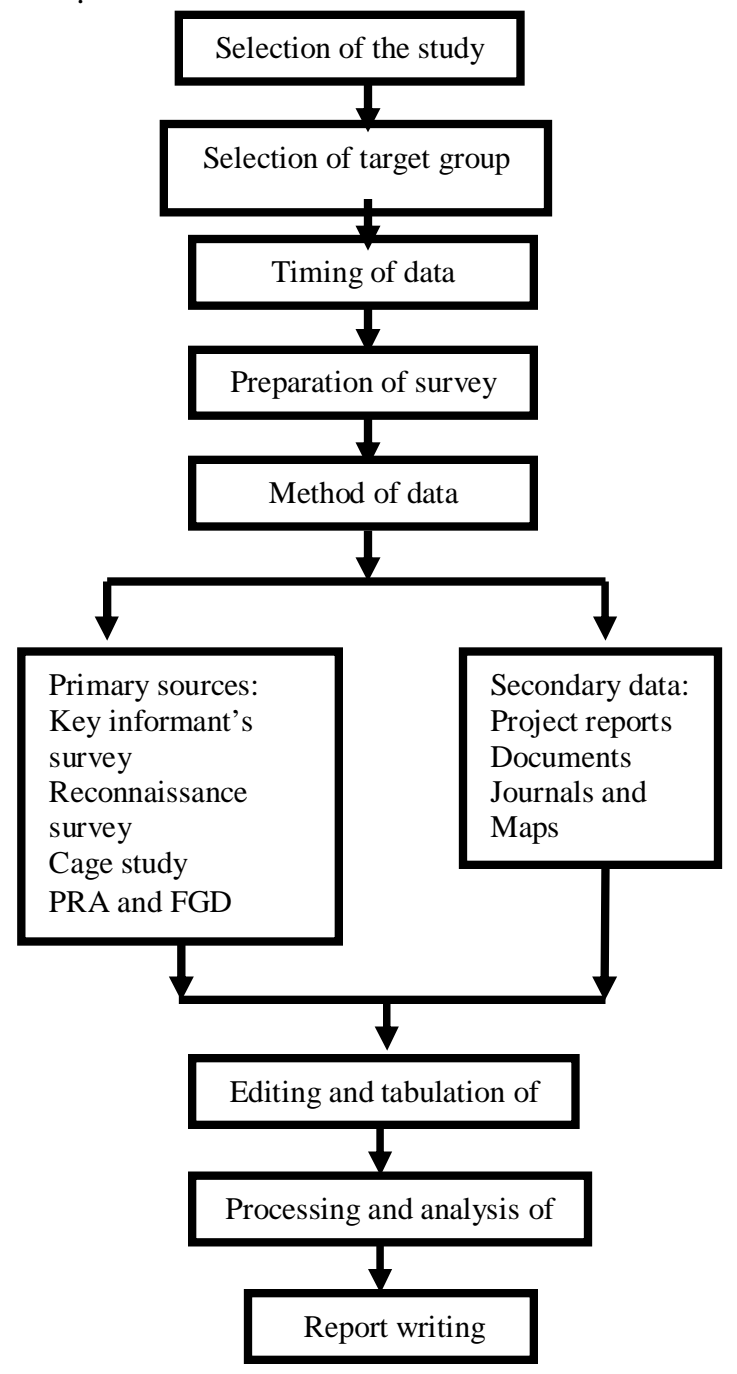

Figure 1. An overview of the steps followed for the study.

Annual income:

Annual incomes of the fishermen varied from BDT 24000 to 50000 . The selected fishermen were grouped into three categories based on the level of annual income and it was found that about $62.5 \%$ of the fishermen had annual income between BDT 24000 to 35000 and $25 \%$ of the respondent had income in the range of BDT 35001 to 45000 and $12.5 \%$ from 45001 to 50000 .

Housing condition:

The nature of house usually indicates the social status of the people. During the survey attempts were made to find out the condition of living house of the people. From the survey, it was found that $60 \%$ households of the fishermen were tin shed with bamboo. $30 \%$ households were tin shed with tin wall and $10 \%$ households were made of straw components.

Sanitary facilities:

It was observed that sanitary conditions of the fishermen were very poor. In the study area, it was found that $80 \%$ of toilets were earthen while $15 \%$ were semi-concrete and $5 \%$ of the fishermen had no sanitary facilities. There was no concrete sanitation found in the investigation. The present study revealed that the sanitary conditions of the fishermen were not satisfactory than fish farmers in Mymensingh district ${ }^{[9]}$ where $62.5 \%$ of the farmers had semi-concrete, $25 \%$ had earthen and $12.5 \%$ of the farmers used concrete sanitation.

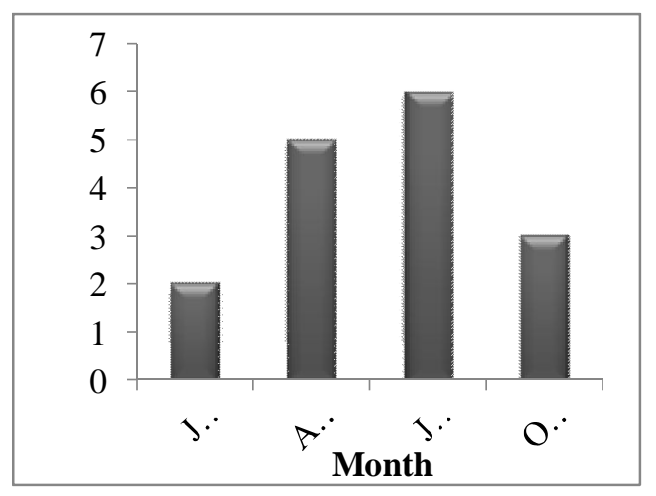

Figure 2. Variation of water depth in Dhaka beel.

Electricity facilities:

From the present survey, it was found that $30 \%$ of the people had electricity facilities and others didn't which is more or less similar to the findings of others [11].

Gears used:

Several form of gears were being used in the Dhaka beel region by the fishermen as jhaki jal, dharma jal, current jal, moiya jal, ber jal, thella jal, bair, chandi bair, borshi etc.

Drinking water facilities:

The provision of clean and safe drinking water is considered to be the most valued elements in the society. The study showed that $100 \%$ of fishermen households used tube-wells water for drinking purposes and among them $60 \%$ fishermen used their own tube-well, $30 \%$ fishermen used shared tube-well and remaining $10 \%$ used neighbors tube-well.

Comparative productions in Dhaka beel:

In the Dhaka beel the annual production was $2.4 \mathrm{mt}$ in 2009. Beel nursery management has increased the annual production and in 2010 it produced excess of $4.7 \mathrm{mt}$ and the annual production become $7.10 \mathrm{mt}$ (Table 5) ${ }^{[8]}$.

Problems faced by the fishermen:

A number of problems were reported by the fishermen including poor level of knowledge, nonavailability of adequate equipments during fishing period, lack of money, lack of credit source, natural disasters and influence of the local heads. Livelihood outcomes: 
Livelihood outcomes can be thought as the inverse of poverty. Contributing to the eradication of poverty and food insecurity, depends on equitable access to resources, access of disadvantaged groups to sufficient, safe and nutritionally adequate food ${ }^{[12]}$. The survey suggested that $80 \%$ of the interviewed fishermen improved their livelihood status through beel nursery project where $20 \%$ of the fishermen failed to do so. Impact of beel nursery project were reflected in the process of increased saving, investment and purchasing capacity which have been increased and unemployment problem was decreased for both men and women.

Fisheries impact:

Beel nursery project increased the average fisheries production in the Dhaka beel from $2.4 \mathrm{mt}$ to $7.10 \mathrm{mt}$ in 2010. The average annual income gained from the beel was also increased from 1.31 lakh to 3.9 lakh tk. Mainly the carp fishes were stocked in the beel and managed for four to five months. Harvested fishes included more than the stocked species. Many of the non stocked species were available as the species got the chance of recruitment.

Comparison of fishing in Dhaka beel before and after beel nursery management:

Before the beel nursery management the fisheries condition of the Dhaka beel was not satisfactory. The economic condition of the fishers was very severe. Beel nursery management practice has brought a dramatic change (Table 6). Average income of the fishermen was doubled than the previous time ${ }^{[8] \text {. }}$

\section{CONCLUSION}

The sustainability of beel fisheries resources are especially important both from ecological and economic point of view. Due to the proper beel nursery management the annual production had increased from $2.4 \mathrm{mt}$ to $7.10 \mathrm{mt}$ in the studied Dhaka beel. Different fish species were disappearing from the beel where beel management practice has created the opportunity of their recruitment. The findings suggested that beel nursery project is economically profitable than the fish fry releasing program. It is clear that community based beel nursery management in the water areas may be an excellent example to stimulate income generation, employment opportunity and to supply nutrition for ensuring sustainable livelihood security.

\section{REFERENCES}

1. DoF (2010). Fishery Statistical of Yearbook of Bangladesh 2008-2009. Fisheries Resources survey system, Department of Fisheries, Ministry of Fisheries and Livestock, Dhaka, pp.46.

2. Ali MI (1999). Society and community based management under the New
Fisheries Management Policy. ICLARM Conf. Proc. 58, p.73-76.

3. IUCN Bangladesh (1998). List of Threatened Animals in Bangladesh. Paper presented in the Special Workshop on Bangladesh Red Book of Threatened Animals. 22 February 1998, Dhaka.

4. Blaxter L, Hughes $\mathrm{C}$ and Tight $\mathrm{M}$ (1996). How to Research. Open University Press, Buckingham, pp.263.

5. Islam MR (2006). Study on fish farming and the Livelihood of the fish farmers in sadar Upazila of Lalmonirhat district. M.S. Thesis, Department of Aquaculture, BAU, Mymensingh.

6. Biswas D (2003). Study of the impact of Aquaculture in and around fish farms in Mymensingh. M. S. Thesis, Department of Fisheries Management, Bangladesh Agricultural University, Mymensingh.

7. DoF (2005). Fisheries Fortnight Compendium, Department of Fisheries, Ministry of Fisheries and livestock, Dhaka, Bangladesh. pp. 46.

8. Upazila Fisheries Office (2011). Annual District Fisheries Report, Madhupur Upazila Fisheries Office, Madhupur, Tangail.

9. Ali H, Azad MAK, Anisuzzaman M, Chowdhury MMR, Hoque $\mathrm{M}$ and Sharful MI (2009). Livelihood status of the fish farmers in some selected areas of Tarakanda upazila of Mymensingh district. J. Agrofor. Environ, 3(2): 8589.

10. Bhaumik U and Saha SK (1994). Perspectives on socio-economic status of the fishermen engaged in fishing in the estuaries of sundarbans. Environ. Ecol., 12(1): 181.

11. Alam MS, Flowra FA, Salam MA and Ali H (2009). Fishing gears, ish marketing and livelihood status of the poor fishermen around the Basantapur beel at lalpur upazila. Journal of 
Agrofor. Environ. (Accepted). Fisheries Management, BAU, Mymensingh.

12. Scones I (1998). Sustainable rural livelihood: a frame work for analysis.
IDS working paper No. 72. Brighton: IDS, UK. 